\title{
Traceable Value for Proficiency Test of Natural Gas
}

Yohanes Susanto Ridwan ${ }^{1}$, Supriadi ${ }^{2}$, Willy Cahya Nugraha ${ }^{1}$

${ }^{1}$ Research Unit for Clean Technology, Indonesian Institute of Sciences, Bandung, Indonesia

${ }^{2}$ Support Laboratory, PT Pertamina EP Asset 3 Jatibarang Field, Indonesia

Correspondence: E-mail: yoha004@lipi.go.id

\begin{abstract}
A B S T R A C T
The use of consensus values as the assign value for proficiency testing (PT) activities are currently a common practice in Indonesia, including the field of natural gas analysis. Hence, mostly the performance evaluation is based on consensus agreement. In this work, a PT was conducted using traceable values with respect to ISO/IEC 17043 and ISO 13528. It was demonstrated that the chosen PT scheme has good capability to evaluate the performance of participating laboratories. And, in some cases, the selected PT scheme was not affected by extreme values and limited number of participants. Post analysis to the PT round has been conducted using the information of uncertainty of the traceable value and the uncertainty of robust average of participants ' results. It was demonstrated that there were no significance biases in the PT round. Moreover, it could be concluded that the participating laboratories have a good agreement one to another. They also have a good agreement with traceable values, giving more additional confidence to the measurement quality in this field of analysis.
\end{abstract}

\begin{tabular}{l}
\hline A R T I C L E I N F O \\
\hline Article History: \\
Submitted/Received 26 Jan 2019 \\
First revised 16 Apr 2019 \\
Accepted 15 Jun 2019 \\
First available online 17 Jun 2019 \\
Publication date 01 Sep 2019 \\
\hline Keywords: \\
Natural gas, \\
Proficiency testing, \\
Traceable assign value, \\
Uncertainty
\end{tabular}




\section{INTRODUCTION}

Indonesia is listed in the top 12 of countries with biggest reserve of natural energy resources (Andika and Valentina, 2016), such as natural gas and coal. Natural gas is a gaseous fossil fuel, which mainly consist of methane $\left(\mathrm{CH}_{4}\right)$. It also contains heavier hydrocarbon molecules such as ethane $\left(\mathrm{C}_{2} \mathrm{H}_{6}\right)$, propane $\left(\mathrm{C}_{3} \mathrm{H}_{8}\right)$, butane $\left(\mathrm{C}_{4} \mathrm{H}_{10}\right)$, pentane $\left(\mathrm{C}_{5} \mathrm{H}_{12}\right)$, hexane $\left(\mathrm{C}_{6} \mathrm{H}_{14}\right)$. Nitrogen $\left(\mathrm{N}_{2}\right)$, carbon dioxide $\left(\mathrm{CO}_{2}\right)$, hydrogen sulfide $\left(\mathrm{H}_{2} \mathrm{~S}\right)$, water $\left(\mathrm{H}_{2} \mathrm{O}\right)$, and small amount of mercury are also exist in various composition depend to its source (Khan et al., 2015). Natural gas is an important commodity since it is could be used as energy for power plants, industries, household, transport vehicles, and also as raw material to fertilizer, petrochemical, and polymer industries. Considering the variety of natural gas usage in our daily life, one could easily see that laboratory testing activities dealing with natural gas is exuberant. Many stakeholders depend on the validity of testing results, based of which they will make many important decisions (Omer, 2007).

Validity of measurement results are very important, therefore quality control effort is inevitable for testing laboratories. Intensive escalation in number of testing laboratories being accredited by Indonesia's National Accreditation Body (KAN) in the last two decades has been promoted and strengthened the implementation of both internal and external quality control in testing laboratories. Proficiency testing (PT) plays an important role as it provides laboratories with an external quality control measure by which one laboratory performance is compare to other laboratories. PTs in the area of natural gas composition are also indespensable for asssuring the quality of and laboratories.

This article provided practical results and evaluation of PT in the area of natural gas composition using metrologically traceable assigned values. Since common proficiency testing in Indonesia use consensus value of participants' results, thus this results would be valuable to stakeholders who interested in the quality of testing laboratories in this field.

PT is a kind of interlaboratory comparison which aimed to evaluate the performance of participating laboratories. It is essential for successful implementation of national quality system (Tholen, 2011). It also provides an important element to assure the validity of measurements conducted by many different laboratories (Ponomareva and Shpakov, 2011). Accreditation body also can use it as an indicator of the performance of laboratories in particular area of testing. Another benefit gained from interlaboratory comparison is that it could provides historical information of spesific laboratory performance for certain period of time, which would be beneficial for the analytical improvement of the laboratory itself (Sykes, 2012).

Participation in PT schemes is necessary and beneficial for all testing laboratories. Many PT schemes have conducted across the world in various area of testing, such as in environmental (Asiah, 2017), water analysis (Song, 2010), physical properties (Hegazy et al., 2010), human serum (Carter et al., 2010), clinical (Tamiru et al., 2015), microbiology (Smith, 2015), and food (Dajay et al., 2019). In developing countries, where the history of the implementation of laboratory quality management system are not as long as in the developed ones, the existence of regular PT schemes are very significant and beneficial. However, there are several obstacles faced by PT providers in the organization of PT schemes, such as affordability for the cost of participation, transport of PT samples, and custom issues for regional and international PTs (Koch, 2019). In certain area, the number of 
participants are very limited and this will add another difficulty to the scheme (Wong, 2011). PT provider also should be aware the potency of collusion and falsification by participants, as these will diminish the confidence of stakeholders (Briggs, 2018).

PT provider will usually deals with abundance of raw data and data processing in order to make the performance evaluation, hence, the implementation of statistical principles and techniques are unavoidable. Statistical method plays important role in the PT results (Hegazy et al., 2010). Two important variables in PT are the assigned value $\left(X_{\mathrm{PT}}\right)$ and target standard deviation $\left(\sigma_{\mathrm{PT}}\right)$. There are several ways to get the assign value: 1) formulation, 2) certified value, 3) reference value, 4) consensus of expert laboratories, and 5) consensus of participants. The use of consensus value of participants in PTs has been the most popular scheme in Indonesia, as well as in many other developing countries (Beckert and Fischer, 2018), however, it's traceability property is the lowest among other assign values. The use of traceable assign value for certain will serve better for the evaluation the performance of participating laboratories (Chen et al., 2014). In the Asia-Pacific region, there is now an increasing needs for traceable assign values to be used in PT schemes (Kaarls et al., 2017).

\section{MATERIALS AND METHODS}

\subsection{PT Sample preparation}

As much as 29 stainless steel gas cylinders was prepared from certified gas standard manufactured by Air Liquid Indonesia. All of the cylinders was put in serial arrangement and equipped with thermometer and pressure gauge (see Figure 1). Sampling method was referred to GPA Standard 2166: 05 (purging-fill and empty method), and was conducted simultaneously at $28 \mathrm{psi}$ and $79^{\circ} \mathrm{C}$. Out of 29 cylinders, 10 were randomly taken for the homogeneity test and 3 cylinders were taken for stability test.

The properties that have been prepared for the PT round were included chemical composition (methane, ethene, propane, ibutane, n-butane, i-pentane, n-pentane, hexane plus, nitrogen, and carbon dioxide, as well as physical properties (gross heating value and compressibility factor).

Homogeneity and stability tests were done for all of those properties. For the homogeneity test, the 10 random samples were analysed in duplicate, resulting in 10 pairs of data. Statistical manipulation was done to extracted the varian of data within duplicates and the varian of data between samples, hence the inhomogeneity, $S_{s}$, could be estimated properly. Samples were considered to have sufficient homogeneity when $S_{s} \leq 0.3 \times \sigma_{P T}$, where the inhomogeneity will not adversely affect the evaluation of participants ' performance . Similar principles were applicated for stability test, in which the average values obtained in homogeneity test, $Y_{\text {Hom }}$, were compared to the average values obtained in the stability tests, Ystab (usually done by measuring at least 3 retain samples in duplicate after certain period of time). The absolute difference between the two thus become the basis to evaluate the stability according to $\left|\gamma_{\text {Hom }}-\gamma_{\text {Stab }}\right| \leq 0.3 \times \sigma_{P T}$ equation, where the instability will not adversely affect the evaluation of participants' performance. 


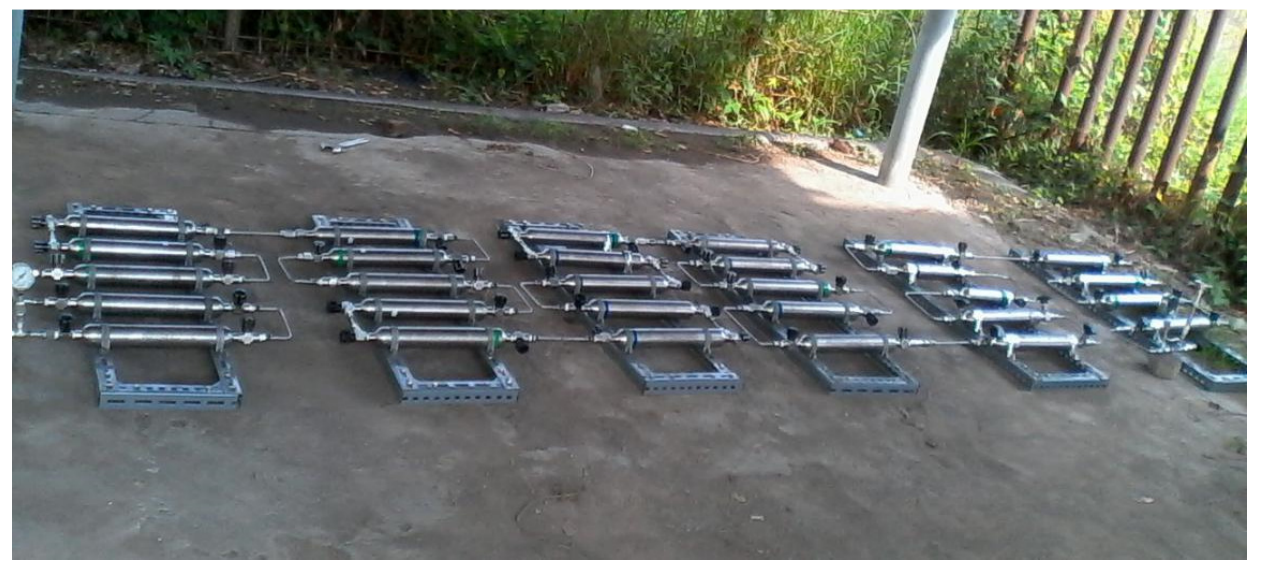

Figure 1. Arrangement of gas cyliders for preparation of PT samples.

\subsection{PT Scheme}

There were 12 participants of the PT registered for the PT round which consist of govermental and private laboratories. After homogeneity test has performed, a kick off meeting was arrange to distributing PT samples to the participants, as well as to introduce the PT scheme, time table, technical guide concerning analytical methods, the date for analysis, and the date for reporting of results.

The scheme for the statistical evaluation of the PT was caried out based on ISO 13528:2005. Assign value, $X_{P T}$, is the value based on which the results of individual laboratory will be evaluated for its bias, whereas the $\sigma_{P A}$ is used to measure how big were the biases using the standardized scoring method. In this PT sheme, the values comes from certificate of the gas standard were taken as the $X_{P T}$ for the PT, whereas the $\sigma_{\mathrm{PT}}$ were taken from the reproducibility standard deviation obtained form reference methods of American Society for Testing and Material, ASTM.

Table 1 provides a compilation of the assign values and target standard deviations for all properties in the PT scheme. Performance evaluation of the laboratories was done using $z$ scores, which obtained by calculating the ratio of the difference between result of each individual laboratory with the assign value, and the target standard deviation, as expressed in this $\boldsymbol{z}_{\boldsymbol{i}}=$ $\frac{\left(x_{i}-x_{P T}\right)}{\sigma_{P T}}$ equation.

Table 1. Compilation of assign values and target standard deviations.

\begin{tabular}{|c|c|c|c|c|c|}
\hline Chemical Properties (Unit) & $X_{\mathrm{PT}}$ & $\sigma_{P T}$ & Physical Properties (Unit) & $X_{\mathrm{PT}}$ & $\sigma_{P T}$ \\
\hline Methane, $\mathrm{CH}_{4}(\% \mathrm{~mol})$ & 75.37 & 0.5276 & $\begin{array}{l}\text { Ideal gross heating value, } \\
\text { GHV }\left(\mathrm{BTU} / \mathrm{Ft}^{3}\right)\end{array}$ & $\begin{array}{c}947.862 \\
3\end{array}$ & 1.6586 \\
\hline Ethane, $\mathrm{C}_{2} \mathrm{H}_{6}(\% \mathrm{~mol})$ & 2.56 & 0.0512 & Compressibilty factor, $\mathrm{Z}$ & 0.9969 & 0.0010 \\
\hline Propane, $\mathrm{C}_{3} \mathrm{H}_{8}$ (\% mol) & 2.50 & 0.0500 & & & \\
\hline i-butane, i- $\mathrm{C}_{4} \mathrm{H}_{10}$ (\% mol) & 0.53 & 0.0212 & & & \\
\hline n-butane, $\mathrm{n}-\mathrm{C}_{4} \mathrm{H}_{10}(\% \mathrm{~mol})$ & 0.51 & 0.0204 & & & \\
\hline i-pentane, i- $\mathrm{C}_{5} \mathrm{H}_{12}(\% \mathrm{~mol})$ & 0.30 & 0.0180 & & & \\
\hline n-pentane, $\mathrm{n}-\mathrm{C}_{5} \mathrm{H}_{12}(\% \mathrm{~mol})$ & 0.30 & 0.0180 & & & \\
\hline Hexane plus, $\mathrm{C}_{6} \mathrm{H}_{14}{ }^{+}(\% \mathrm{~mol})$ & 0.40 & 0.1200 & & & \\
\hline Nitrogen, $\mathrm{N}_{2}(\% \mathrm{~mol})$ & 2.53 & 0.1771 & & & \\
\hline Carbon dioxide, $\mathrm{CO}_{2}(\% \mathrm{~mol})$ & 15.00 & 1.800 & & & \\
\hline
\end{tabular}


Based on $z$ scores, performance of individual laboratory could be evaluated. The conventional interpretation of $z$ score, according to ISO/IEC $17043: 2010$ is as follows:

(a) a result that gives $|z| \leq 2.0$ is considered to be acceptable,

(b) a result that gives $2.0<|z|<3.0$ is considered to give warning signal,

(c) a result that gives $|z| \geq 3.0$ is considered to be uncceptable. Laboratories that has an unacceptable performance should investigate for the cause of the problem and initiate a corrective action.

\section{RESULTS AND DISCUSSION}

\subsection{Homogeneity and stability of samples}

Several series of measurements have been performed for the homogeneity test. Statistical manipulation was conducted to calculating the standard deviation between samples, $\mathrm{S}_{\mathrm{s}}$ and make comparison to the homogeneity criteria of $0.3 \times \sigma_{\mathrm{PT}}$. The samples were showed to be sufficiently homogeneous for almost all the examined properties, except for "ideal gross heating value, GHV". It is explained in the ISO 13528 that when the criteria for sufficient homogeneity is not met, the provider could include the inhomogeneity into the target standard deviation. Hence, the alternative target standard deviation, $\boldsymbol{\sigma}_{\boldsymbol{P T}}^{\prime}$ should be calculated according to $\sigma_{P T}^{\prime}=\sqrt{\sigma_{P T}^{2}+S_{S}^{2}}$ equation. In the case of GHV, this method was applicated. Two weeks after sample preparation, the stability test were performed by conducting duplicate analysis to three archive samples. All of the properties were showed to have sufficient stability for the PT scheme. Results of the homogeneity and stability tests as presented in Table 2 confirmed that the PT samples were proper for the PT round.

Table 2. Results of homogeneity and stability test.

\begin{tabular}{|c|c|c|c|c|c|c|}
\hline Properties (Unit) & $\mathbf{Y}_{\text {Hom }}$ & Ss & Hom test & $\mathbf{Y}_{\text {Stab }}$ & $\left|Y_{\text {hom }}-Y_{\text {stab }}\right|$ & Stab test \\
\hline \multicolumn{7}{|c|}{ Chemical Properties: } \\
\hline $\mathrm{CH}_{4}(\% \mathrm{~mol})$ & 75.3187 & 0.0280 & Pass & 75.3278 & 0.0091 & Pass \\
\hline $\mathrm{C}_{2} \mathrm{H}_{6}(\% \mathrm{~mol})$ & 2.5352 & 0.0094 & Pass & 2.5300 & 0.0052 & Pass \\
\hline $\mathrm{C}_{3} \mathrm{H}_{8}(\% \mathrm{~mol})$ & 2.5056 & 0.0024 & Pass & 2.4977 & 0.0079 & Pass \\
\hline $\mathrm{i}-\mathrm{C}_{4} \mathrm{H}_{10}(\% \mathrm{~mol})$ & 0.5316 & 0.0009 & Pass & 0.5283 & 0.0033 & Pass \\
\hline $\mathrm{n}-\mathrm{C}_{4} \mathrm{H}_{10}(\% \mathrm{~mol})$ & 0.5092 & 0.0014 & Pass & 0.5077 & 0.0015 & Pass \\
\hline $\mathrm{i}-\mathrm{C}_{5} \mathrm{H}_{12}(\% \mathrm{~mol})$ & 0.2987 & 0.0017 & Pass & 0.2981 & 0.0006 & Pass \\
\hline $\mathrm{n}-\mathrm{C}_{5} \mathrm{H}_{12}(\% \mathrm{~mol})$ & 0.2997 & 0.0019 & Pass & 0.2956 & 0.0042 & Pass \\
\hline $\mathrm{C}_{6} \mathrm{H}_{14}^{+}(\% \mathrm{~mol})$ & 0.4354 & 0.0220 & Pass & 0.4452 & 0.0098 & Pass \\
\hline $\mathrm{N}_{2}(\% \mathrm{~mol})$ & 2.5570 & 0.0181 & Pass & 2.5797 & 0.0227 & Pass \\
\hline $\mathrm{CO}_{2}(\% \mathrm{~mol})$ & 15.0090 & 0.0042 & Pass & 14.9900 & 0.0190 & Pass \\
\hline \multicolumn{7}{|c|}{ Physical properties: } \\
\hline $\mathrm{GHV}\left(\mathrm{BTU} / \mathrm{Ft}^{3}\right)$ & 947.204 & 0.8558 & Pass & 947.122 & 0.082 & Pass \\
\hline Z & 0.9969 & 0.00 & Pass & 0.9969 & 0.00 & Pass \\
\hline
\end{tabular}




\subsection{Performance evaluation results}

All participants were expected to conducted analysis in one week after the kick off meeting, and reported the results in the following week after analysis. From 12 registered laboratories, 11 labs were be able to reported the results to PT provider while one laboratory was not be able to conduct measurement due to technical problem within the laboratory. Results are presented graphically in Figure 2. The results were comparable one to another data. In case of $\mathrm{CH}_{4}, \mathrm{C}_{2} \mathrm{H}_{6}, \mathrm{C}_{3} \mathrm{H}_{8}, \mathrm{i}-\mathrm{C}_{4} \mathrm{H}_{10}, \mathrm{n}-\mathrm{C}_{4} \mathrm{H}_{10}, \mathrm{C}_{6} \mathrm{H}_{14}{ }^{+}$, and $\mathrm{CO}_{2}$, there are several extreme values that could easily examined visually in Figure $\mathbf{2}$. Participants with lab code of L-06 gives extreme values in term of 5 positive bias and
1 negative bias, out of 12 properties, indicating that the laboratory has serious biases within its analytical system. However, in general the results from participants were of good agreement and consensus values could be derived for all the properties in the PT scheme.

Performance evaluation of participants was conducted using $z$ score based on the preselected $X_{\mathrm{PT}}$ and $\sigma_{\mathrm{PT}}$. The result of performance evaluation is presented in Table 3. The PT scheme was successfully able to evaluated the performance of participating laboratories. Participants with lab code of L-03, L-08, and L-12 have acceptable performances for all properties being tested, while L-06 was suffered with 6 unacceptable and 2 warning signal results.

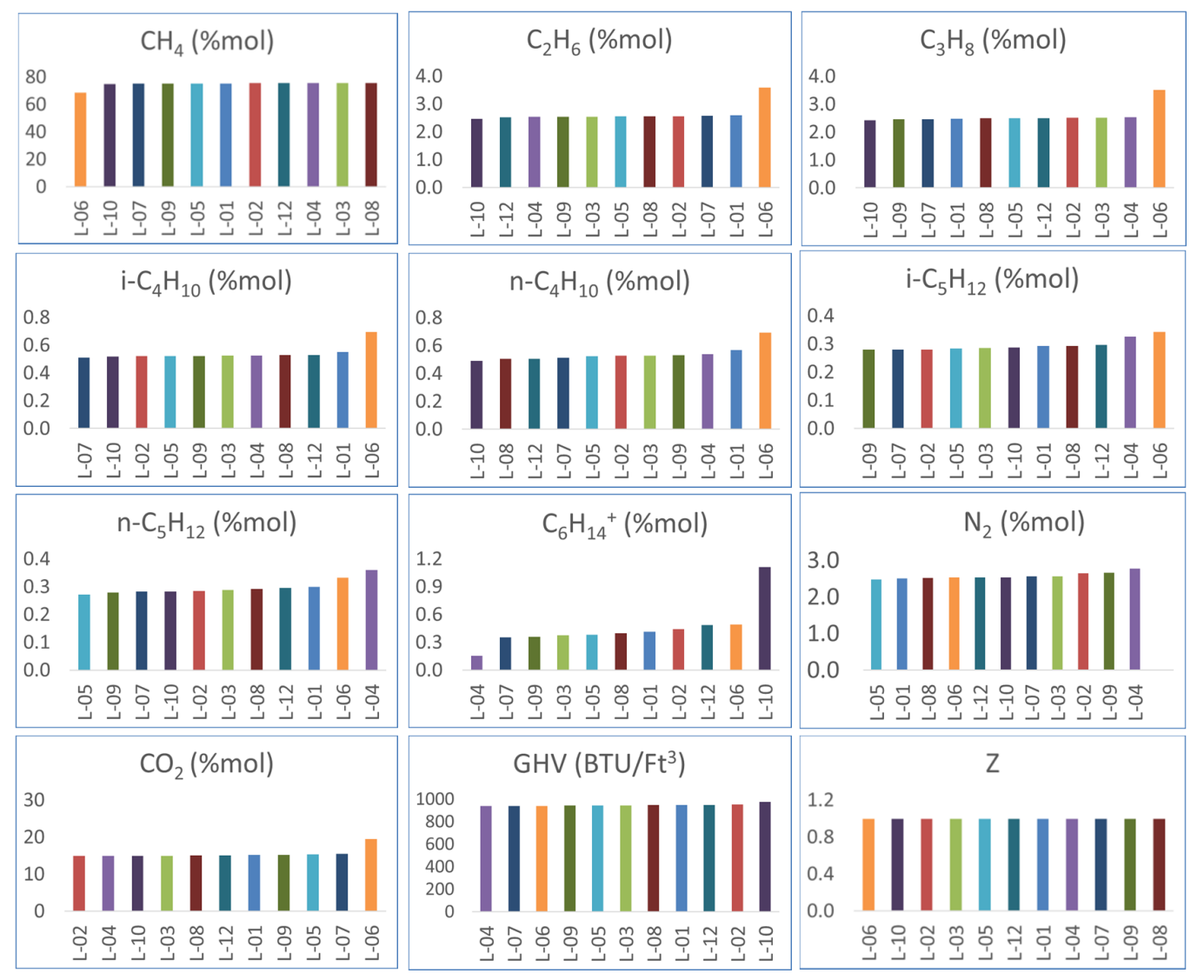

Figure 2. Graphical presentation of participants' results. 
Table 3. Performance evaluation of participants.

\begin{tabular}{|c|c|c|c|c|c|c|c|c|c|c|c|}
\hline Properties & L-01 & L-02 & L-03 & L-04 & L-05 & L-06 & L-07 & L-08 & L-09 & L-10 & $\mathrm{L}-12$ \\
\hline \multicolumn{12}{|l|}{$\mathrm{CH}_{4}$} \\
\hline \multicolumn{12}{|l|}{$\mathrm{C}_{2} \mathrm{H}_{6}$} \\
\hline \multicolumn{12}{|l|}{$\mathrm{C}_{3} \mathrm{H}_{8}$} \\
\hline \multicolumn{12}{|l|}{$\mathrm{i}-\mathrm{C}_{4} \mathrm{H}_{10}$} \\
\hline \multicolumn{12}{|l|}{$\mathrm{n}-\mathrm{C}_{4} \mathrm{H}_{10}$} \\
\hline \multicolumn{12}{|l|}{$\mathrm{i}-\mathrm{C}_{5} \mathrm{H}_{12}$} \\
\hline \multicolumn{12}{|l|}{$\mathrm{n}-\mathrm{C}_{5} \mathrm{H}_{12}$} \\
\hline \multicolumn{12}{|l|}{$\mathrm{C}_{6} \mathrm{H}_{14^{+}}$} \\
\hline \multicolumn{12}{|l|}{$\mathrm{N}_{2}$} \\
\hline \multicolumn{12}{|l|}{$\mathrm{CO}_{2}$} \\
\hline \multicolumn{12}{|l|}{ GHV } \\
\hline z & & & & & & & & & & & \\
\hline
\end{tabular}

$\left({ }^{*}\right)=$ = pass (acceptable), $\square=$ warning signal, $\square=$ unacceptable

\subsection{PT evaluation}

Post analysis was conducted to evaluate the bias of overall PT round, considering the assign value, $X_{\mathrm{PT}}$, and its uncertainty, $\boldsymbol{\mu}\left(\boldsymbol{x}_{\boldsymbol{P} T}\right)$, and the robust average from participants' values, $X_{\mathrm{RA}}$, and its uncertainty, $\boldsymbol{\mu}\left(\boldsymbol{x}_{\boldsymbol{R} A}\right)$.

Since the $\boldsymbol{x}_{\boldsymbol{P} T}$ for the PT round was the certified value given in the certificate, hence $\boldsymbol{\mu}\left(\boldsymbol{x}_{\boldsymbol{P} T}\right)$ could easily estimated from the quoted uncertainty stated in the certificate. Mean while $X_{R A}$ obtained from Algorithm A, a well known statistical technique used to obtained robust parameters. Its uncertainty, $\boldsymbol{\mu}\left(\boldsymbol{x}_{\boldsymbol{R} A}\right)$, was calculated using robust standard deviation obtained from Algorithm A, $\sigma_{\text {robust }}$, according to $\boldsymbol{\mu}\left(\boldsymbol{x}_{R A}\right)=$ $1.25 x \sigma_{\text {robust }} / \sqrt{\boldsymbol{p}}$ equation, where $\mathrm{p}$ is the number of participants' values.

Subsequently, the assign value $X_{\mathrm{PT}}$ were compared with robust value $X_{\mathrm{RA}}$. The absolute difference between the two, $\mid X_{\mathrm{PT}}$ - $X_{\mathrm{RA}} \mid$, was then divided by the standard uncertainty of the difference,
$\sqrt{\boldsymbol{\mu}\left(\boldsymbol{x}_{P T}\right)^{2}+\boldsymbol{\mu}\left(\boldsymbol{x}_{R A}\right)^{2}}$, resulting in a certain ratio. Based on ISO 13528, If the ratio obtained was more than two then there was a considerable bias existed in the PT round. In this case, where certified value was used as assign value, the possible bias could be came from the bias in the measurement method used by participants, or from common bias in the results of laboratories. However, if another assign value was used, e.g., consensus of expert laboratories, then there was additional possibility cause of bias came from the bias of expert lab's consensus itself.

The results of post analysis for the bias of the PT round was presented in Table 4. All the ratio were far less than 2 , indicated that the differences between the selected assign values and the robust averages were not significantly differ. It could be concluded that there were no significant biases in the PT round; moreover it could be concluded that the participants were have sufficient accuracy in the measurement of properties being tested in the PT round. 
Table 4. Evaluation of bias in the results of the PT round.

\begin{tabular}{|c|c|c|c|c|c|c|c|c|}
\hline Properties & $X_{\mathrm{RA}}$ & $\sigma_{\text {Robust }}$ & $\mu\left(X_{R A}\right)$ & $\mu\left(\sigma_{\mathrm{PT}}\right)$ & $\begin{array}{c}\left|X_{\mathrm{RA}}-X_{\mathrm{PT}}\right| \\
(\mathrm{A}) \\
\end{array}$ & $\begin{array}{c}\sqrt{\mu\left(X_{R A}\right)^{2}+\mu\left(X_{P T}\right)^{2}} \\
\text { (B) }\end{array}$ & $\begin{array}{l}\text { Ratio } \\
\text { (A/B) }\end{array}$ & Bias \\
\hline $\mathrm{CH}_{4}$ & 75.20 & 0.207 & 0.0780 & 1.155 & 0.170 & 1.1573 & 0.147 & No \\
\hline $\mathrm{C}_{2} \mathrm{H}_{6}$ & 2.56 & 0.056 & 0.0211 & 1.155 & 0.000 & 1.1549 & 0.000 & No \\
\hline $\mathrm{C}_{3} \mathrm{H}_{8}$ & 2.49 & 0.034 & 0.0128 & 1.155 & 0.010 & 1.1548 & 0.009 & No \\
\hline $\mathrm{i}-\mathrm{C}_{4} \mathrm{H}_{10}$ & 0.525 & 0.008 & 0.0030 & 1.732 & 0.005 & 1.7321 & 0.003 & No \\
\hline $\mathrm{n}-\mathrm{C}_{4} \mathrm{H}_{10}$ & 0.526 & 0.022 & 0.0083 & 1.732 & 0.016 & 1.7321 & 0.009 & No \\
\hline $\mathrm{i}-\mathrm{C}_{5} \mathrm{H}_{12}$ & 0.289 & 0.009 & 0.0034 & 1.732 & 0.011 & 1.7321 & 0.006 & No \\
\hline $\mathrm{n}-\mathrm{C}_{5} \mathrm{H}_{12}$ & 0.29 & 0.012 & 0.0045 & 1.732 & 0.010 & 1.7321 & 0.006 & No \\
\hline $\mathrm{C}_{6} \mathrm{H}_{14}^{+}$ & 0.407 & 0.072 & 0.0271 & 1.732 & 0.007 & 1.7323 & 0.004 & No \\
\hline $\mathrm{N}_{2}$ & 2.548 & 0.048 & 0.0181 & 1.155 & 0.018 & 1.1548 & 0.016 & No \\
\hline $\mathrm{CO}_{2}$ & 15.059 & 0.138 & 0.0520 & 1.155 & 0.059 & 1.1559 & 0.051 & No \\
\hline GHV & 945.404 & 6.183 & 2.3303 & 0.380 & 2.458 & 2.3611 & 1.041 & No \\
\hline Z & 0.9969 & 0.00015 & 0.0001 & 0.000 & 0.000 & 0.0001 & 0.000 & No \\
\hline
\end{tabular}

\section{CONCLUSION}

Performance evaluation of the participating laboratories using traceable value is very valuable, considering that the use of consensus value is currently a populer common practice, especially in the field of gas analysis. The use of traceable assign values have no doubt that they have been capable to evaluate the performance of participating laboratories. Moreover, post analysis were done to evaluate the bias of the PT round, and there were no apparent bias were observed. This results give additional confidence to the quality of the testing laboratories in this field of analysis.

\section{ACKNOWLEDGEMENTS}

The present review includes sample preparation and analytical measurements works which were supported by Support Laboratory, PT. Pertamina EP Asset 3 Jatibarang Field.

\section{AUTHORS' NOTE}

The author(s) declare(s) that there is no conflict of interest regarding the publication of this article. Authors confirmed that the data and the paper are free of plagiarism.

\section{REFERENCES}

Andika, R., and Valentina, V. (2016). Techno-economic Assessment of Coal to SNG Power Plant in Kalimantan. Indonesian Journal of Science and Technology, 1(2), 156-169.

Asiah (2017). Mapping of environmental laboratory competency through proficiency testing program for heavy metal in clean water. Ecolab, 11(2), 53-104.

Beckert, S. F., and Fischer, G. E. (2018). Interlaboratory comparison of roughness measurement: Application of Algorithm A of ISO 13528: 2015 in determining the designated value and the standard deviation. In Journal of Physics: Conference Series, 1065(8), 082007 
Briggs, P. (2018). Collusion and falsification of results in proficiency testing. Journal of Physics: Conference series, 1065, 212001.

Carter, G. D., Berry, J. L., Gunter, E., Jones, G., Jones, J. C., Makin, H. L. J., Wheeler, M. J. (2010). Journal of steroid biochemistry and molecular biology proficiency testing of 25hydroxyvitamin d (25-ohd) assays. Journal of Steroid Biochemistry and Molecular Biology, 121(1-2), 176-179.

Cheng, S., Mesquida, C., Gui, E. M., Cheow, P. S., Lee, T. K., and Teo, T. L. (2014). Providing a traceable assigned value in a proficiency testing programme on the determination of benzoic acid in orange juice. Accreditation and Quality Assurance, 19(6), 439-443.

Dajay, L. C., Portugal, T. R., Climaco, J. C., Parcon, M. R. V., Udarbe, M. A., Placio, R. E. E., \& Adona, P. E. (2019). Establishment of proficiency testing programs in the Philippines. Accreditation and Quality Assurance, 24(1), 65-71.

Hegazy, R., Mohamed, M. I., and Abu-Sinna, A. (2010). A comparative study of statistical methods used in analyzing the proficiency testing results of yield stress. Mapan, 25(2), 107-113.

Kaarls, R., Mackay, L., Samuel, A., Sin, D. W. M., Mok, C. S., Wong, Y. L., and Yip, Y. C. (2017). Laboratory capacity building through the use of metrologically traceable reference values in proficiency testing programmes. Accreditation and Quality Assurance, 22(6), 321-334.

Khan, M. I., Yasmin, T., and Shakoor, A. (2015). Technical overview of compressed natural gas (CNG) as a transportation fuel. Renewable and Sustainable Energy Reviews, 51, 785797.

Koch, M. (2019). Changes to proficiency testing in developing countries over the last 10 years. Accreditation and Quality Assurance, 24(1), 9-12.

Omer, A. M. (2007). Renewable energy resources for electricity generation in Sudan. Renewable and Sustainable Energy Reviews, 11(7), 1481-1497.

Ponomareva, O. B., and Shpakov, S. V. (2012). Testing the proficiency of analytical laboratories by means of interlaboratory comparison tests- an important element in assurance of the uniformity of measurements. Measurement Techniques, 54(12), 5861.

Smith, R. (2015). Analyst interpretation of results: experience from microbiology proficiency testing. Accreditation and Quality Assurance, 20(4), 325-327.

Song, Y. K. J. L. K. (2010). A review of proficiency testing scheme in Republic of Korea : in the field of water analysis. Accreditation and Quality Assurance, 15, 251-254.

Sykes, M. (2012). Proficiency testing for the improvement of analytical practice. Accreditation and Quality Assurance, 17, 467-471.

Tamiru, A., Boulanger, L., Chang, M. A., Malone, J. L., and Aidoo, M. (2015). Field assessment of dried Plasmodium falciparum samples for malaria rapid diagnostic test quality control and proficiency testing in Ethiopia. Malaria Journal, 14(11), 1-8. 
279 | Indonesian Journal of Science \& Technology, Volume 4 Issue 2, September 2019 page 270-279

Tholen, D. (2011). Metrology in service of society: the role of proficiency testing. Accreditation and Quality Assurance, 16, 603-605.

Wong, S. K. (2011). Performance evaluation for proficiency testing with a limited number of participants. Accreditation and Quality Assurance, 16(11), 539. 